\title{
Sphaerodoridae (Annelida: Polychaeta) from the Bellingshausen Sea (Antarctica) with the description of two new species
}

\author{
J. Moreira ${ }^{1}$ J. Parapar ${ }^{2}$ \\ ${ }^{1}$ Estación de Bioloxía Mariña da Graña, Universidade de Santiago de Compostela, Rúa da \\ Ribeira 1, 15590 A Graña, Ferrol, Spain e-mail: juan.moreira@usc.es \\ ${ }^{2}$ Departamento de Bioloxía Animal, Facultade de Ciencias, Universidade da Coruña, 15008 A \\ Coruña, Spain
}

Polar Biology, Volume 34, Issue 2, pp 193-204

Received: 21 April 2010 / Revised: 30 June 2010 / Accepted: 14 July 2010 / Published online: 29 July 2010

\section{Cite this article as:}

Moreira, J. \& Parapar, J. Polar Biol (2011) 34: 193. doi:10.1007/s00300-010-0869-x

The final publication is available at Springer via http://dx.doi.org/10.1007/s00300-010-0869-x

\begin{abstract}
The examination of polychaete collections obtained during the Spanish Bentart 2006expedition to the Bellingshausen Sea (Antarctica) revealed the presence of several sphaerodorid species. In this work, species belonging to the genera Sphaerodorum Örsted, 1843, Ephesiella Chamberlin, 1919, Clavodorum Hartman and Fauchald, 1971 and Sphaerephesia Fauchald, 1972 are reported including two new species belonging to Sphaerodorum and Sphaerephesia, respectively. A specimen identified as Ephesiella sp. might also represent a new species but, due to its poor state of preservation, a formal description is not possible yet. Furthermore, Sphaerodoropsis polypapillata HartmannSchröder and Rosenfeldt, 1988 is transferred to the genus Clavodorum Hartman and Fauchald, 1971 after examination of the type series and specimens obtained from the Bellingshausen Sea.
\end{abstract}

\section{Keywords}

Polychaeta; Sphaerodoridae; Bellingshausen Sea; Antarctica; Benthos; New species

\section{Introduction}

Sphaerodorids (Polychaeta, Sphaerodoridae) are small polychaetes characterized by having a variable number of tubercles and papillae on the dorsum, which can be sessile or stalked, or arranged in a definite, non-random pattern (Fauchald 1974). In general, sphaerodorids are presumed to be overlooked in many sampling programmes due to their small size and inappropriate processing of samples (Borowski 1994). Although taxonomic and ecological knowledge of this family is still scarce in many geographic areas, sphaerodorids of Antarctic seas are comparatively better known (Fauchald 1974; Hartman 1978; Hartmann-Schröder and Rosenfeldt 1992; Schüller and Ebbe 2007). To date, 13 species have been described as having their type locality in Subantarctic and/or Antarctic 
waters; these belong to the genera Sphaerodorum Örsted, 1843 (one species), Ephesiella Chamberlin, 1919 (3), Clavodorum Hartman and Fauchald, 1971 (2) and Sphaerodoropsis Hartman and Fauchald, 1971 (7) (see Ehlers 1913; Benham 1921; Hartman 1967; Averincev 1972; Fauchald 1974; Hartmann-Schröder and Rosenfeldt 1988, 1990, 1992). In addition, Hartmann-Schröder and Rosenfeldt (1990) reported the presence of the genus Ephesiopsis Hartman and Fauchald, 1971 in Elephant Island after one fragmented specimen. Other species, which were supposed to have a cosmopolitan distribution, such as Sphaerodorumgracilis (Rathke, 1843) and Sphaerodoropsis minuta Webster and Benedict, 1887, have also been recorded in Antarctic latitudes; in many cases, these records refer actually to other sphaerodorid taxa which turned out to be new species (Fauchald 1974).

The Bellingshausen Sea (Antarctica) constitutes a natural connection between the Ross Sea and the Antarctic Peninsula and is of great zoogeographical importance because of its role in the dispersion of species around the waters of the Antarctic continent and with South America through the Scotia Arc (Sáiz et al. 2008). Nevertheless, the Bellingshausen Sea has been less studied than the Weddell and Ross Seas and the Antarctic Peninsula, where many research programmes have been carried out in the last years (e.g., Arntz et al. 1994; Hartmann-Schröder and Rosenfeldt 1988; Brandt et al. 2004; Hilbig et al. 2006). This is due, in part, to its remoteness and the prevalence of ice during most of the year there. In consequence, little information is available on the polychaete fauna of the Bellingshausen Sea in general, including that referred to sphaerodorids. In this context, the Spanish expeditions Bentart 2003 and Bentart 2006 were carried out in order to study the composition and distribution of the benthic fauna in the shelf and slope of the Bellingshausen Sea and adjacent areas.

The examination of the polychaete collections obtained during the Bentart 2006 expedition revealed the presence of several sphaerodorid species. All specimens belonging to the genera Sphaerodorum, Ephesiella, Clavodorum and Sphaerephesia Fauchald, 1972 are reported here, including two new species belonging to Sphaerodorum and Sphaerephesia; Sphaerodoropsis material will be described elsewhere. In addition, Sphaerodoropsis polypapillata Hartmann-Schröder and Rosenfeldt, 1988 is transferred to the genus Clavodorum after examination of the type series and specimens obtained from the Bellingshausen Sea.

\section{Materials and methods}

The material examined comes from samples obtained during the Spanish Bentart 2006expedition at the Bellingshausen Sea (from the Antarctic Peninsula to Thurston Island) and off the western Antarctic Peninsula (from Gerlache Strait to Marguerite Bay). Most of the sphaerodorid specimens were collected with a modified Macer-GIRO-Q Epibenthic Sledge (Cartes et al. 1994); an additional specimen was obtained by means of an Agassiz trawl (Station BS 29). Sampling methodology, location and physical features of the stations where sphaerodorids were found are described in detail in San Vicente et al. (2009).

Observations, drawings and measurements of specimens were made using an Olympus BX40 compound microscope connected to a drawing tube. All specimens were deposited at the Museo Nacional de Ciencias Naturales (MNCN), Madrid, Spain. Specimens used for scanning electron microscopy (SEM) were dehydrated in a graded ethanol series, prepared by critical-point drying using $\mathrm{CO}_{2}$, coated with gold in a BAL-TEC SCD 004 evaporator and examined and photographed under a JEOL JSM-6400 scanning electron microscope at the Servicios de Apoio á Investigación, Universidade da Coruña (SAIN), Spain. The nomenclature of prostomial appendages follows that of Aguirrezabalaga and Ceberio (2005). The macrotubercle located dorsally to the parapodium has been 
considered by several authors as the dorsal notopodial cirrus (e.g., Ruderman 1911; Pleijel 2001). In this paper, dorsal cirri are not specifically described because, if present, they would not differ from the other dorsal macrotubercles. The code of stations refers to the sampling area: BS, Bellingshausen Sea; WAP, western Antarctic Peninsula. The abbreviations for the structures referred in the figures are the following: ap, dorsal antenniform papilla; cl, chaetal lobe; dp, distal papilla; ia, intermediate lateral antenna; ldp, latero-dorsal papilla; lp, lateral papilla; ma, median antenna; mt, microtubercle; MT, macrotubercle; pa, palps; pc, peristomial cirrus; vc, ventral cirrus; vp, ventral papilla.

\section{Results and discussion}

Taxonomic account

Family Sphaerodoridae Malmgren, 1867

Sphaerodorum olgae sp. nov. (Figs. 1, 2, 3)

\section{Material examined}

St. BS 38, one complete specimen, $10.7 \mathrm{~mm}$ long, $0.3 \mathrm{~mm}$ wide, with 77 chaetigers (Holotype, MNCN 16.01/13158). St. BS 30, one spec. (Paratype, MNCN 16.01/13159). St. BS 31, one spec. (Paratype, MNCN 16.01/13160). St. BS 33, 3 spec. (Paratypes, MNCN 16.01/13161). St. BS 34, one spec. (Paratype, MNCN 16.01/13162).

\section{Description}

Specimens measuring 6.1-11.2 mm long, 0.17-0.37 mm wide, with 60-90 chaetigers. Body long, tapering distally; yellowish-whitish in ethanol. Tegument wrinkled, with a granulated appearance (Fig. 2b). Prostomium bluntly rounded, fused to peristomium (Figs. 1a, b, 2a). Median antenna and three pairs of lateral prostomial appendages (palps, intermediate antennae, and dorsal antenniform papillae). Median antenna clavate. Intermediate antennae and palps digitiform, longer than median antenna. Dorsal antenniform papillae digitiform, shorter than intermediate antennae and palps; contracted and difficult to detect in some specimens. One pair of peristomial cirri, digitiform, slightly shorter than palps and intermediate antennae. Prostomium and peristomium with papillae; about 8-10 papillae among prostomial paired appendages. Eyes and pharynx not seen. Two dorso-lateral macrotubercles per chaetiger (Fig. 1e); spherical to pear-shaped, provided with terminal papilla. From chaetiger 2 posteriorly two microtubercles per chaetiger, dorsal to macrotubercles, with a basal collar and a long terminal papilla (Fig. 1d). Macrotubercles and microtubercles arranged in four longitudinal rows. Papillae on all body surfaces. About four dorsal transversal rows of papillae per chaetiger, numbering approximately 20 papillae. About 5-6 ventral transversal rows of papillae per chaetiger, numbering more than 30 papillae. Some papillae on lateral surfaces among parapodia. Total number and arrangement of body papillae difficult to ascertain due to contraction of specimens and wrinkled appearance of tegument.

Parapodia uniramous, longer than wide (Figs. 1f, g, 2c-e). Parapodia of first chaetiger in ventral position; following parapodia lateral. Digitiform chaetal lobe, arising dorsally among chaetae, projecting beyond acicular lobe. Ventral cirri cylindrical, usually with a distal protuberance, longer and thicker than chaetal lobe, surpassing acicular lobe tip. Parapodia with about 9-11 digitiform papillae, shorter than chaetal lobe: one distal papilla, one on latero-dorsal parapodial face, 2-3 on each lateral face and 2-3 on ventral surface medial to ventral cirrus; papillae on ventral surfaces more spherical than those on lateral and dorsal surfaces. Parapodia of last chaetigers reduced. Recurved 
hooks in first chaetiger (one per parapodium), visible in ventral view (Fig. 1b, 2f). Simple chaetae usually numbering 4 per fascicle, with small subdistal boss (Fig. 3a, b); distal end falciform, pointed. Spinulation along internal border, from distal end to subdistal boss; some spinulation along external border. Most chaetae with a suture-like depression somewhat separating distal end and subdistal boss (Fig. 3c-d); when observed in the compound microscope appearing as if blade is fused to shaft.

Pygidium with two dorsal macrotubercles and midventral digitiform anal cirrus (Fig. 1c).
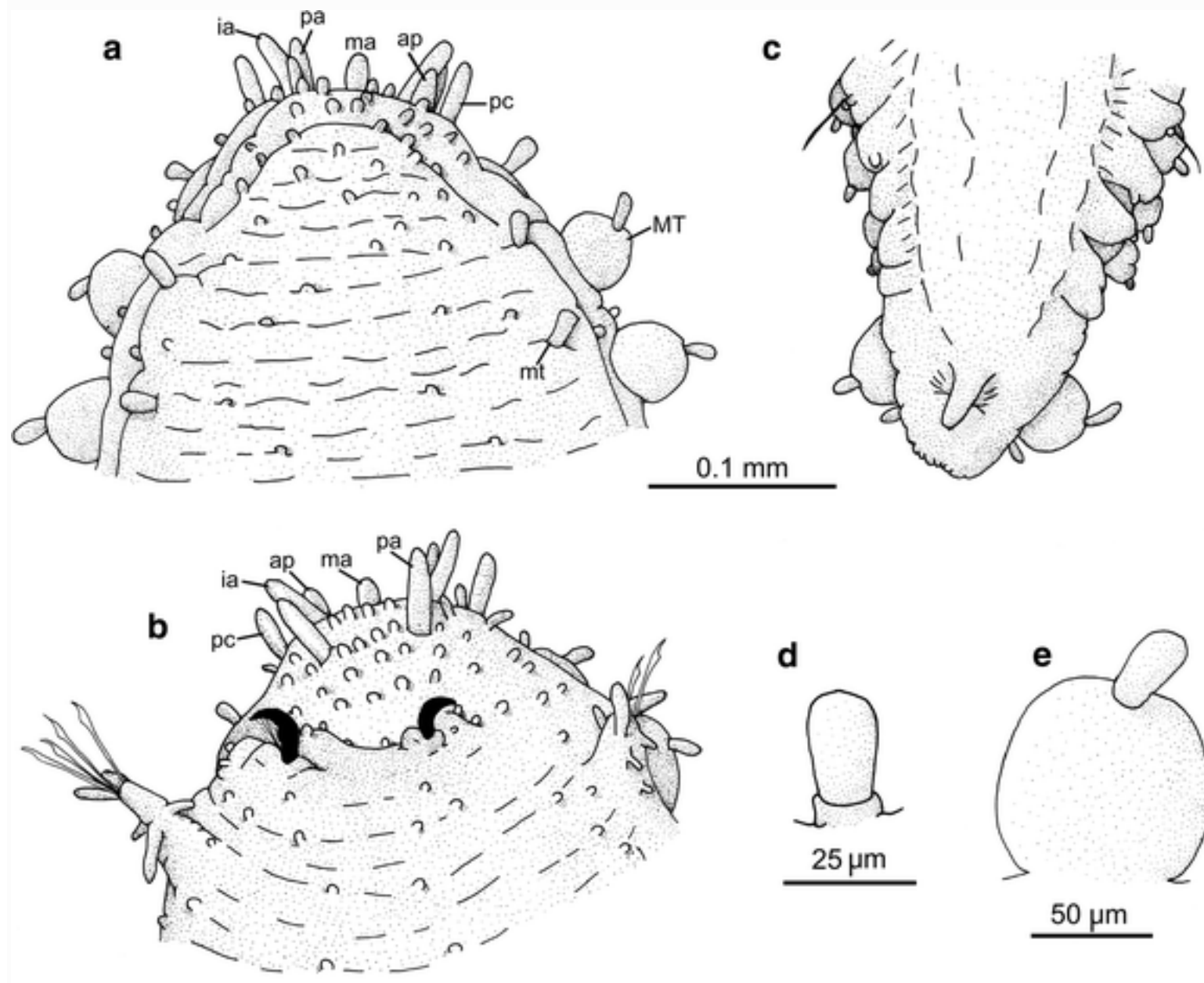

$0.1 \mathrm{~mm}$
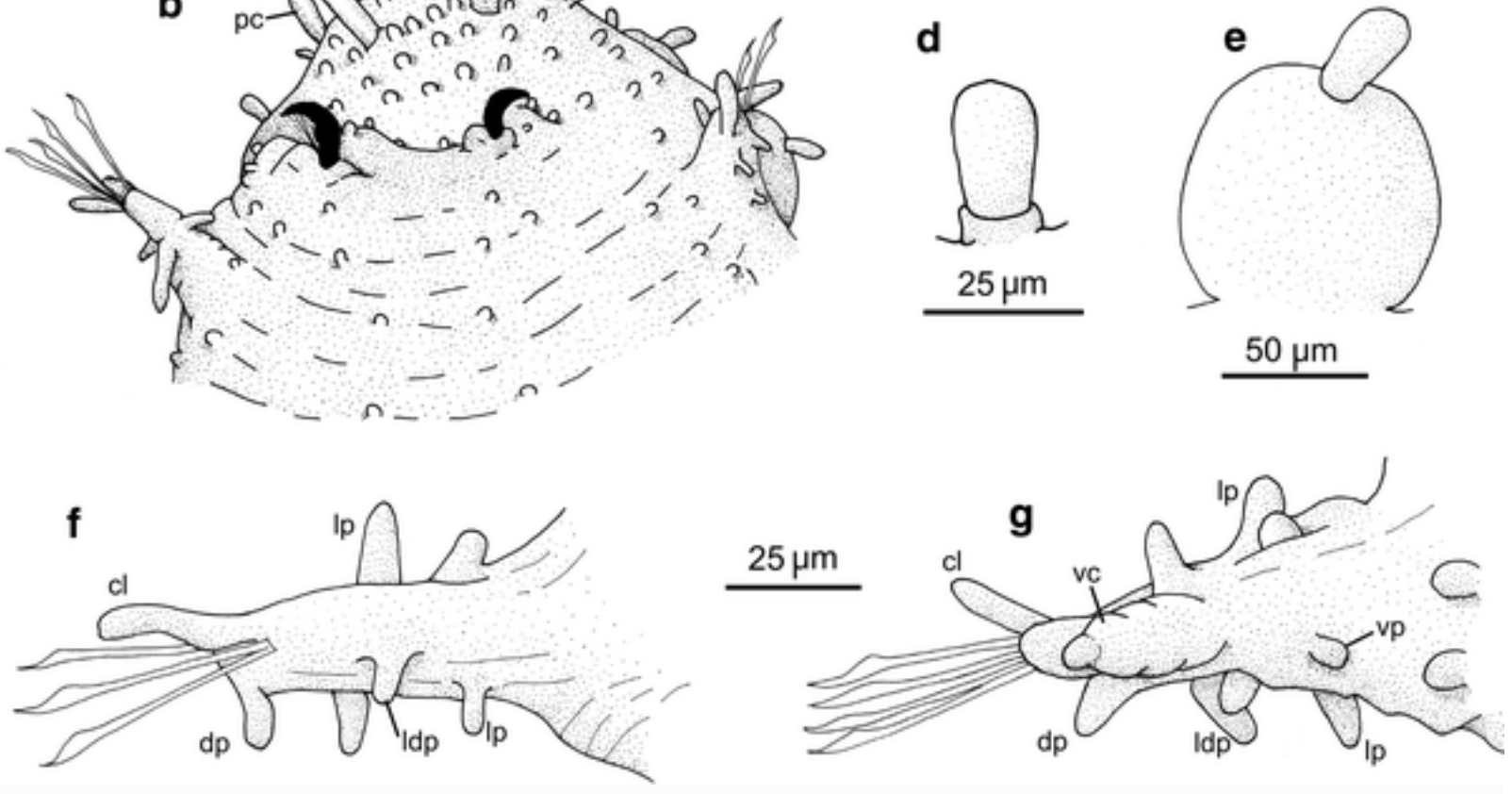

Fig. 1 Sphaerodorum olgae sp. nov. a anterior end, dorsal view, $\mathbf{b}$ anterior end, ventral view, $\mathbf{c}$ pygidium, ventral view, $\mathbf{d}$ dorsal microtubercle, e dorsal macrotubercle, fparapodium, chaetiger 7, dorsal view, $\mathbf{g}$ parapodium, chaetiger 16 , ventral view. $\mathbf{a}-\mathbf{c}, \mathbf{f}-\mathbf{g}$, same scale 


\section{Remarks}

The new species differs mostly from the other six species of the genus in the features of the parapodium including number and arrangement of papillae. Thus, $S$. olgae sp. nov. differs from Sphaerodorumindutum Fauchald, 1974 and S. papillifer Moore, 1909 in having less parapodial papillae; those of $S$. indutum are larger and number at least 15 while those of $S$. papillifer are numerous on each parapodial face, small and conical in shape. In S. recurvatum Fauchald, 1974, the parapodia lack papillae and body papillae are absent from the dorsum, whereas in $S$. olgae sp. nov. body papillae are present both on the dorsum and venter. Sphaerodorum gracilis(Rathke, 1843) also has a parapodium with a similar number of papillae to that of $S$. olgae sp. nov. but these species differ in arrangement and size of their parapodial papillae; thus, in $S$. gracilis there are 5-6 papillae
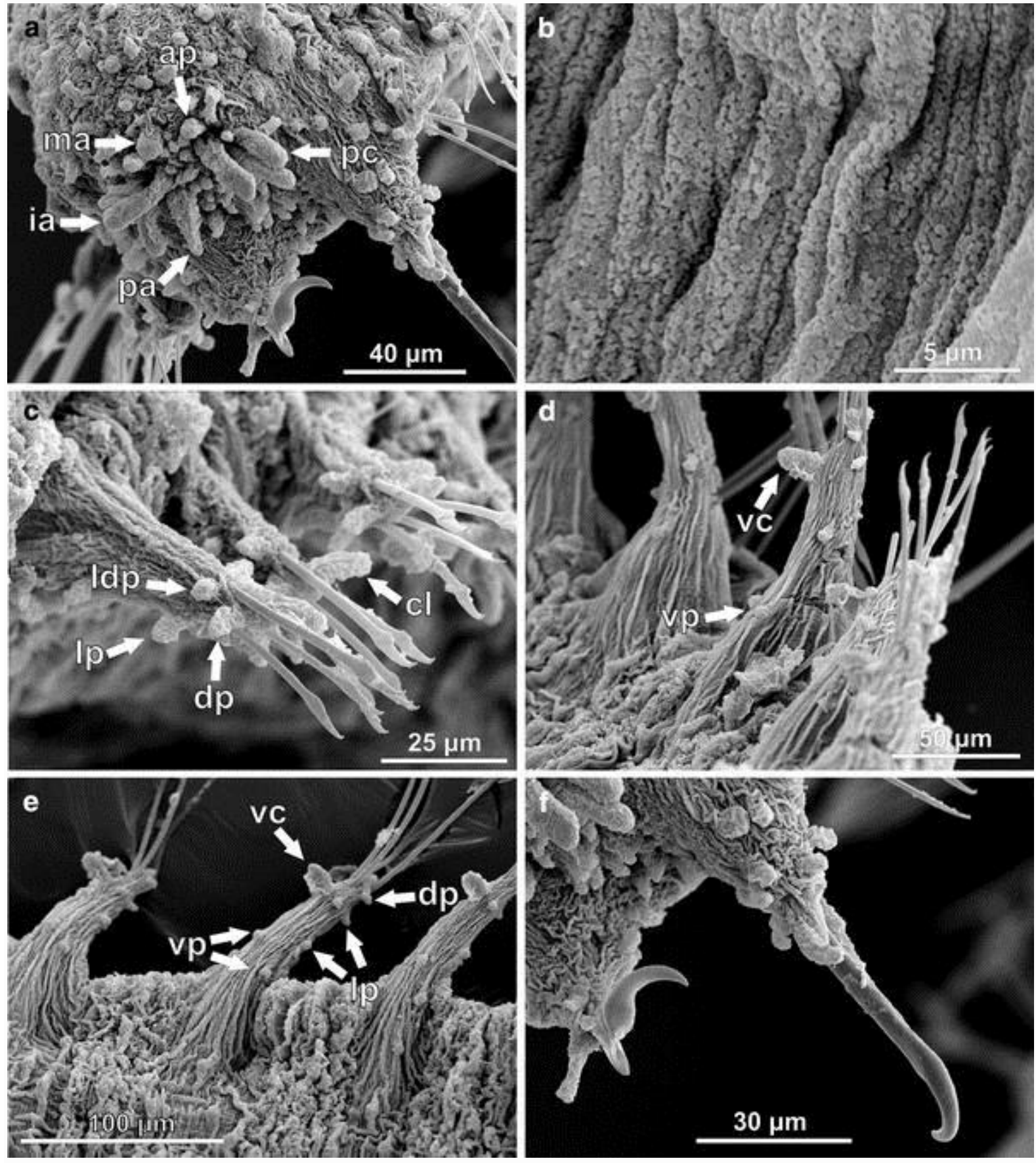

Fig. 2 Sphaerodorum olgae sp. nov. SEM micrographs. a anterior end, frontal view, btegument, c-e mid-body parapodia, f first chaetiger, parapodia and hooks 
regularly distributed along each lateral parapodial surface, which are proportionally smaller than those of S. olgae sp. nov. when compared to the length of the parapodium. In addition, the prechaetal lobe in $S$. gracilis is usually conical rather than digitiform and the body papillae on dorsal surfaces are slightly more numerous than in S. olgaesp. nov. On the other hand, Sphaerodorum olgae sp. nov. differs from $S$. vietnamenseFauchald, 1974 in the shape of the ventral cirri, which are long and slender in the latter; in S. olgae sp. nov., ventral cirri are thick and cylindrical in shape. In addition, the simple chaetae of $S$. vietnamense are of two types, including some strongly recurved ones which are not present in $S$. olgae sp. nov. In fact, the simple chaetae of $S$. olgae sp. nov. are strikingly similar to those of $S$. ophiurophoretos Martín and Alva, 1988; the latter also presents chaetae showing a protuberance which seems to mark the limit between the blade and the shaft (cfr. Fig. 2D in Martin and Alva 1988). Some simple chaetae of S. olgae sp. nov. (cfr. Fig. 2) are similar to the aforementioned chaetae, showing in this case a suture-like depression that makes the simple chaetae looking like a composite one in which the blade is fused to the shaft. Nevertheless, $S$. ophiurophoretos differs from $S$. olgae sp. nov. in having a shorter body, fewer chaetigers (8-9 vs. 60-90) and fewer parapodial papillae; the latter are spherical and similar to those found on the rest of the body instead of being digitiform as in S. olgae sp. nov.

\section{Etymology}

The new species is dedicated to the memory of Dr. Olga Hartman, for her many contributions to our knowledge of the Antarctic polychaete fauna.
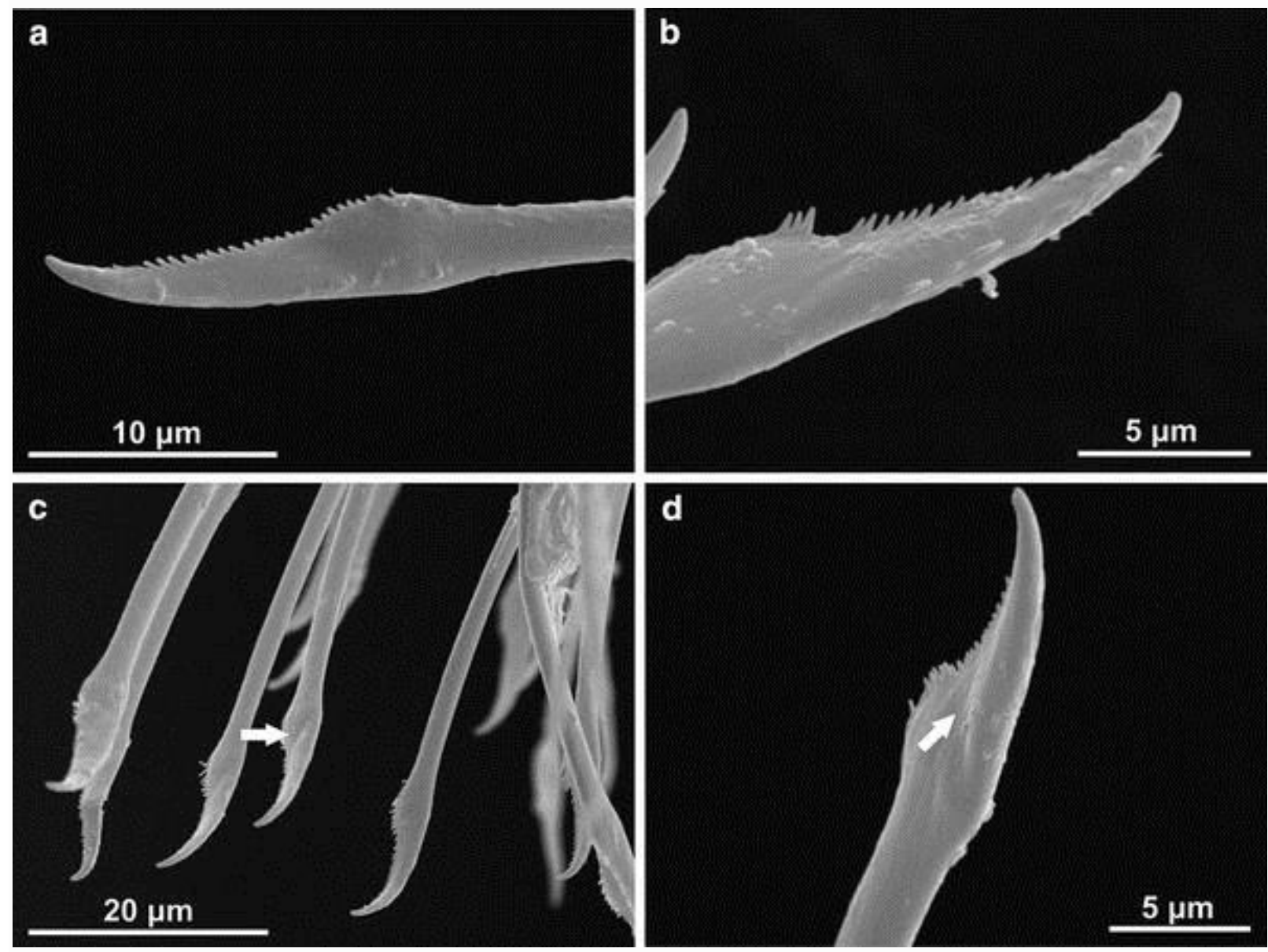

Fig. 3 Sphaerodorum olgae sp. nov. SEM micrographs. a-b simple chaetae, $\mathbf{c}-\mathbf{d}$ simple chaetae with suturelike depression between blade and shaft indicated by white arrows 


\section{Ecology and distribution}

To date, only known from the Bellingshausen Sea in muddy gravel, muddy sand, sandy mud and mud, at depths of 431-1,799 m.

\section{Ephesiella muehlenhardtae Hartmann-Schröder and Rosenfeldt, 1988}

Ephesiella muehlenhardtae Hartmann-Schröder and Rosenfeldt, 1988: 47-48, figs 32-38.

\section{Material examined}

St. BS 29, one complete specimen, $9.5 \mathrm{~mm}$ long, $0.37 \mathrm{~mm}$ wide, with 63 chaetigers (MNCN $16.01 / 13164)$.

\section{Ecology and distribution}

This species is known from Elephant Island and Bransfield Strait (Hartmann-Schröder and Rosenfeldt 1990), in bottoms ranging from gravel and stones to fine sand and silt at depths of 93 342 m (Hartmann-Schröder and Rosenfeldt 1988, 1990, 1992). The only specimen found at the Bellingshausen Sea (Peter I Island; this work) was collected at a muddy bottom at a depth of 3,219$3,280 \mathrm{~m}$, thus extending the known bathymetric range of this species.

\section{Ephesiella sp.}

\section{Material examined}

St. BS 34, one complete specimen, $6.75 \mathrm{~mm}$ long, $0.75 \mathrm{~mm}$ wide, with 48 chaetigers (MNCN $16.01 / 13165)$.

\section{Remarks}

The only specimen available is in poor condition; the prostomium is contracted but one median antenna and two lateral prostomial appendages, all of similar size, are present. The parapodium has a ventral cirrus not projecting beyond the acicular lobe and also bears an oval dorsal papilla in distal position which resembles a prechaetal lobe; each parapodium also bears at least 10-12 papillae scattered along all parapodial surfaces and around the chaetal lobe. The parapodia of the first chaetiger are provided each with one protruding hook; all remaining chaetae are compound falcigers. The other known Antarctic species of the genus Ephesiella, namely E. antarctica (McIntosh, 1885), E. pallida Fauchald, 1974 and E. muehlenhardtae Hartmann-Schröder and Rosenfeldt, 1988, differ from our specimen in the number and arrangement of parapodial papillae. Thus, $E$. antarctica has a nearly smooth parapodium which bears a postchaetal lobe, E. pallida has one prechaetal lobe, one postchaetal lobe and one pair of papillae on each face of the parapodium, and $E$. muehlenhardtae has about 5-6 parapodial papillae and a chaetal lobe (cfr. Hartmann-Schröder and Rosenfeldt 1988, figs 35-37). Although our specimen might represent a new species to science, a formal description is not possible due to its state of preservation.

\section{Ecology and distribution}


The only specimen available was collected in the Bellingshausen Sea in muddy fine sand at depths of $612-620 \mathrm{~m}$.

Clavodorum polypapillata (Hartmann-Schröder and Rosenfeldt,1988) comb. nov. (Figs. 4, 5)

Material examined

St. BS 37, one specimen (MNCN 16.01/13166). St. WAP 41, 3 spec. (MNCN 16.01/13167). St. WAP 43, 5 spec. (MNCN 16.01/13168).

Additional material (type series)

Sphaerodoropsis polypapillata Hartmann-Schröder and Rosenfeldt, 1988, Zoological Museum, Hamburg. Holotype (HZM: P-19161), paratype (HZM: P-19162).

\section{Description}

Bentart 2006 specimens measuring $2.0-3.3 \mathrm{~mm}$ in length and $0.6-1.3 \mathrm{~mm}$ in width, with $22-25$ chaetigers. Body short, grub-like, inflated, lacking pigmentation, transparent-whitish in ethanol (Fig. 5a). Tegument with a granulated appearance (Fig. 5b).

Prostomium bluntly rounded, fused to peristomium; in some specimens a constriction between the peristomium and the rest of the body. Median antenna and two pairs of lateral prostomial appendages (Fig. 4a). Median antenna long, digitiform (Fig. 4b). Intermediate antennae as long as median antenna, with 3 basal digitiform papillae. Palps digitiform, shorter than intermediate antennae, with 3 basal digitiform papillae. Peristomial cirri digitiform, shorter than antennae and palps, with a basal digitiform papilla. Peristomium with dorsal transversal row of about 10 digitiform papillae. Two brown eyes between palps and prostomial paired appendages. Several ventral digitiform papillae between peristomial cirri and mouth (Fig. 4c). Pharynx extending over 3-4 segments. Dorsal macrotubercles spherical, stalked (Fig. 4d). Macrotubercles numbering 12-17 per chaetiger arranged in a transverse row along dorsal and lateral surfaces (Fig. 4e). Spherical microtubercles irregularly distributed among rows of macrotubercles. Ventral surfaces densely covered with microtubercles provided with short stalk (Fig. 4f); microtubercles similar to those on dorsal and lateral body surfaces, the largest slightly smaller than dorsal macrotubercles.

Parapodia uniramous, with wrinkled surface, longer than wide (Figs. 4g, h, 5c). Digitiform prechaetal lobe from chaetiger 7 backwards, projecting beyond acicular lobe; postchaetal lobe absent. Ventral cirri digitiform, slightly shorter than or as long as prechaetal lobe, surpassing acicular lobe tip. Parapodia with 3-4 stalked papillae: one on anterior lateral parapodial face, one on posterior lateral face and 1-2 on ventral surface behind ventral cirrus. Composite chaetae numbering about 10-15 per fascicle; blades unidentate with recurved tip and thin spinules along cutting margin (Fig. 5d). Blades showing gradation in length in the same parapodium; blades about 50-30 $\mu \mathrm{m}$ long in anterior chaetigers and 35-25 $\mu \mathrm{m}$ long in posterior ones.

Pygidium with about 8 small dorsal papillae, two larger spherical lateral papillae and midventral digitiform anal cirrus, the latter slightly longer than parapodial ventral cirri. 


\section{Remarks}

Hartmann-Schröder and Rosenfeldt (1988) described Sphaerodoropsis polypapillata from King George Island (Antarctica) and then reported the same species from Elephant Island (HartmanSchröder and Rosenfeldt 1992). The re-examination of the type series and the additional specimens collected during the Bentart 2006 expedition confirmed the presence of stalked macrotubercles instead of the sessile ones reported in the original description. Macro- and microtubercles are close to each other in the examined specimens which makes difficult to distinguish any stalk. Nevertheless, some specimens including those of the type series had already lost some macrotubercles but not their stalks thus revealing their true morphology. Therefore, $S$. polypapillata is here transferred to the genus Clavodorum because of the possession of stalked tubercles and a median antenna which is at
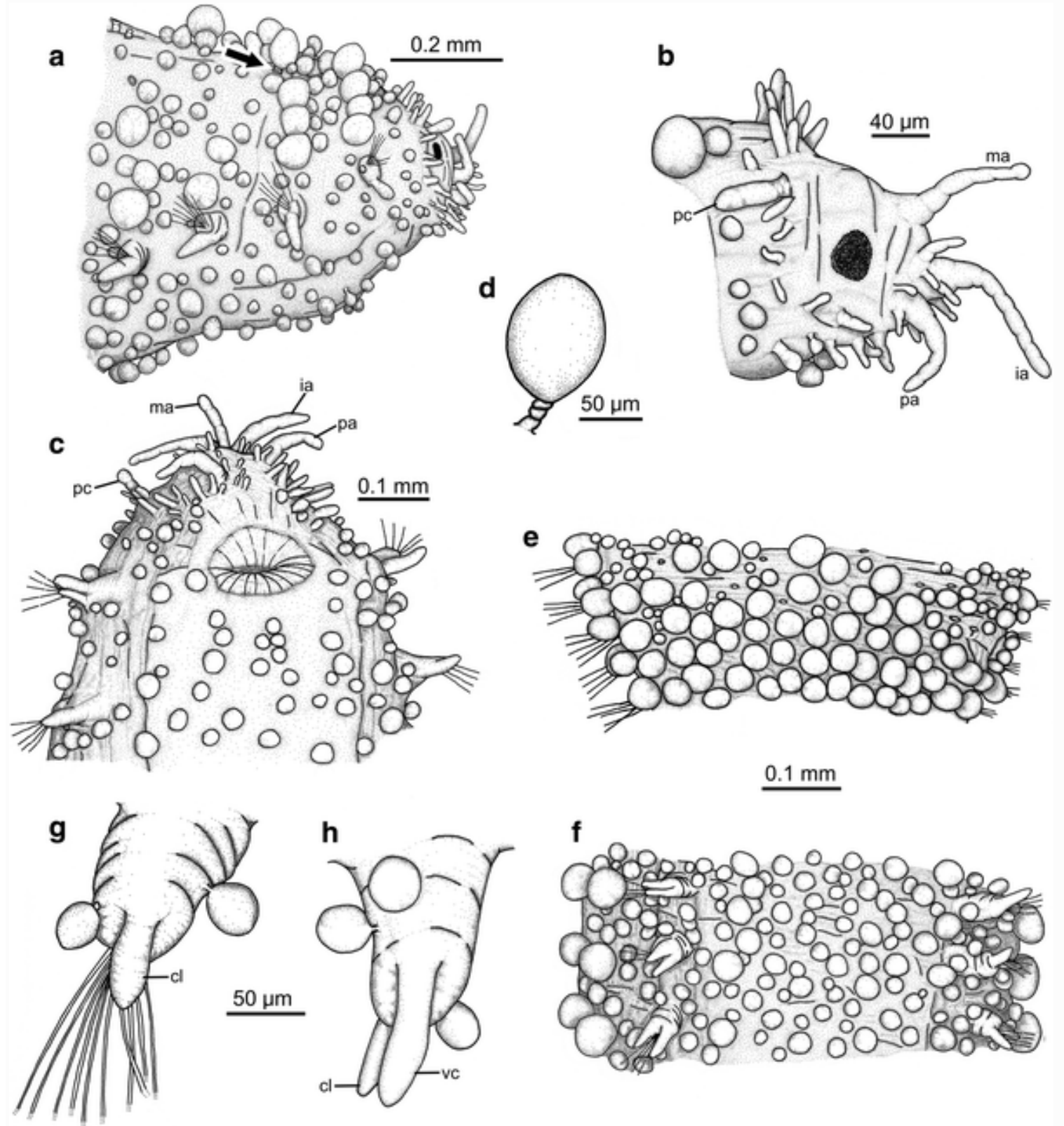

Fig. 4 Clavodorum polypapillata (Hartmann-Schröder and Rosenfeldt, 1988) comb. nov. aanterior end, lateral view (arrow indicates position of macrotubercle stalk), b anterior end, lateral view, detail, c anterior end, ventral view, d stalked macrotubercle, e mid-body segments, dorsal view, f mid-body segments, ventral view, g parapodium, chaetiger 8, dorsal view, h parapodium, chaetiger 8, ventral view (chaetae not illustrated). $\mathbf{e}-\mathbf{f}, \mathbf{g}-\mathbf{h}$, same scale 
Sphaerodoropsis polypapillata Hartmann-Schröder and Rosenfeldt, 1988: 49-50, fig. 45; 1992: 107-108.

least as long as the intermediate ones. The genus Sphaerodoridium Lützen, 1961 also bears stalked macrotubercles but the median antenna is shorter than other prostomial paired appendages and ventral microtubercles are, in general, not stalked (Bakken 2002). Clavodorum polypapillata comb. nov. differs mainly from the other known species of the genus in having more than ten longitudinal rows of macrotubercles. Thus, $C$. bengalorum Fauchald, 1974 bears eight rows of macrotubercles, whereas C. fusum (Hartman, 1967), C. atlanticum Hartman and Fauchald, 1971, C. clavatum Fauchald, 1972, C. adriaticum Katzmann, 1974, C. longipes Fauchald, 1974, C. fauchaldi Desbruyères, 1980, C. mexicanum Kudenov, 1987 and C. antarcticum Hartmann-Schröder and Rosenfeldt, 1990 bear up to six rows of macrotubercles. In addition, Clavodorum andamanense Bakken, 2002 differs from $C$. polypapillata comb. nov. in having dorsal macrotubercles arranged in ten longitudinal rows, the body ventral papillae are less numerous, numbering about six per chaetiger, and the parapodium bears one small postchaetal lobe and is provided with only two papillae instead of 3-4.

\section{Ecology and distribution}

The specimens from the Bentart 2006 expedition were collected at the Bellingshausen Sea and western Antarctic Peninsula in muddy gravel at depths of $246-516 \mathrm{~m}$. This species has previously been reported from soft bottoms of the Weddell Sea ranging from fine sand with stones to silt-clay,
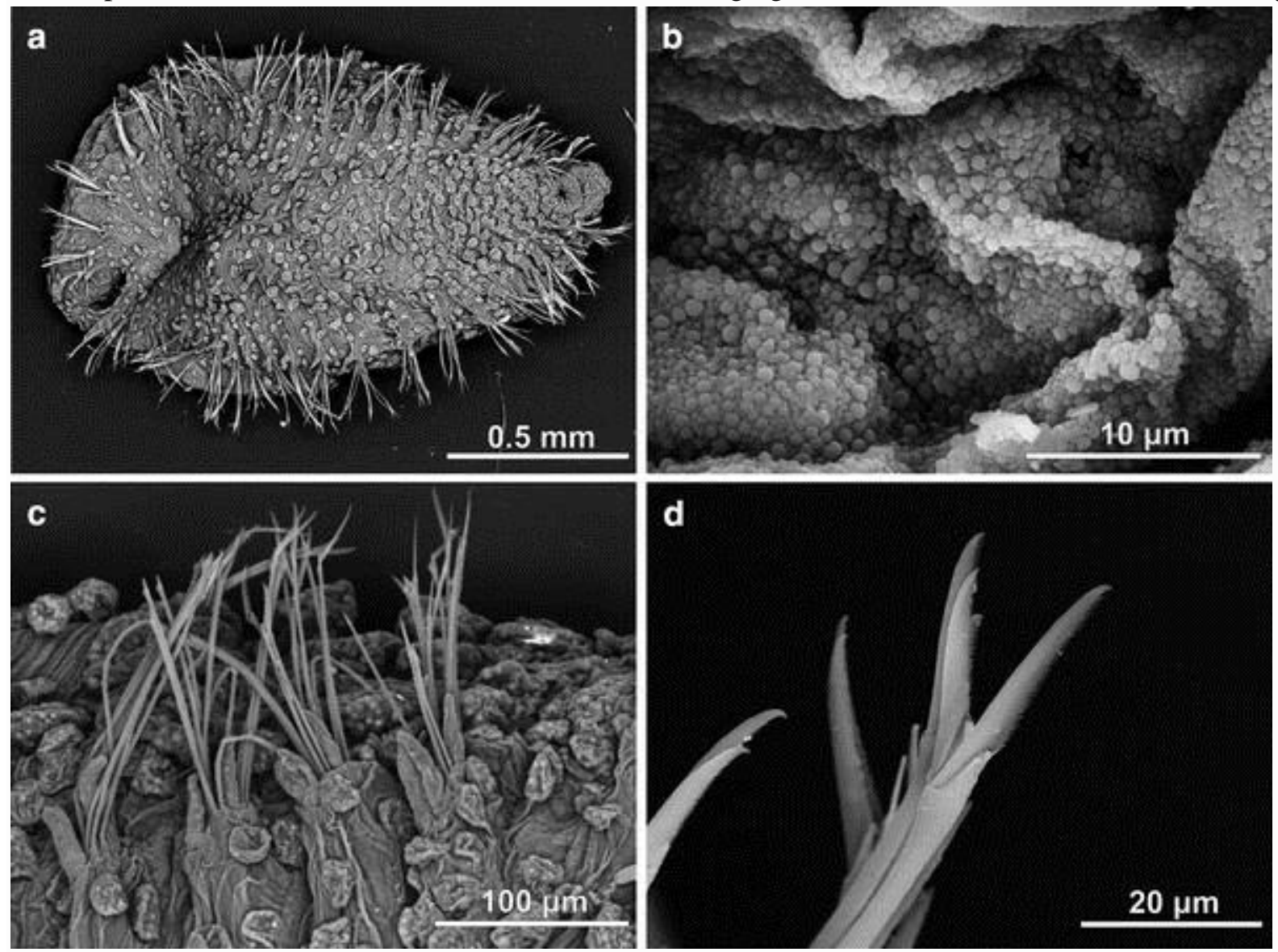

Fig. 5 Clavodorum polypapillata (Hartmann-Schröder and Rosenfeldt, 1988) comb. nov. SEM micrographs. a habitus, ventral view, b tegument, $\mathbf{c}$ mid-body parapodia, ventral view, $\mathbf{d}$ composite chaetae 
at depths of 96-532 m (Hartmann-Schröder and Rosenfeldt 1988, 1990, 1992; Schüller and Ebbe 2007).

Sphaerephesia gesae sp. nov. (Figs. 6, 7)

\section{Material examined}

St. BS 34, one complete specimen, $2.1 \mathrm{~mm}$ long, $0.5 \mathrm{~mm}$ wide, with 11 chaetigers (Holotype MNCN $16.01 / 13163)$.

\section{Description}

Body short, grub-like, lacking pigmentation, tegument transparent-whitish in ethanol. Prostomium bluntly rounded, fused to peristomium (Fig. 6a). Median antenna short, probably contracted; two pairs of lateral prostomial appendages (palps and intermediate antennae), digitiform, longer than the median antenna (Fig. 6b). Six small papillae encircled by lateral paired appendages; six similar papillae around mouth opening. Peristomial cirri digitiform, shorter than lateral paired prostomial appendages. Eyes and pharynx not seen. Dorsal macrotubercles sessile, mostly spherical or rounded, arranged in 10 longitudinal rows forming a zig-zag pattern. Chaetigers 1-2 with ten dorsal macrotubercles each; 12 macrotubercles per segment from chaetiger 3 posteriorly. Macrotubercles arranged in two transversal rows: six macrotubercles on each chaetiger parapodial area and six on the interparapodial area. On each parapodial area the four lateralmost macrotubercles are provided with a digitiform papilla on the top, the other two macrotubercles smooth; the four dorsalmost macrotubercles spherical in shape and the two ventralmost more digitiform (Fig. 6c, d). Macrotubercles on interparapodial areas not provided with papillae. Chaetigers 1-2 with six macrotubercles on parapodial areas and four macrotubercles on interparapodial areas; in chaetiger 2 the two dorsalmost on interparapodial area smaller than the others. Dorsal papillae present between rows of macrotubercles, numbering up to 11 per segment in mid-body, arranged in 11 longitudinal rows following a non-random pattern (Fig. 7a).

Venter with small papillae. Chaetigers 1-4 with up to 10 ventral papillae each, six on each parapodial area (three on each side arranged in a V-shape) and four on each interparapodial area arranged in a line perpendicular line to the anterior-posterior body axis (Fig. 7b). Two additional ventral papillae from chaetiger 5 backwards, one on each side, close to the posteriormost papilla near the parapodial base.

Parapodia uniramous, longer than wide, with one acicula; digitiform prechaetal lobe from chaetiger 5 backwards, projecting beyond acicular lobe (Fig. 6e); postchaetal lobes absent. Ventral cirri digitiform, larger than prechaetal lobe, reaching acicular lobe tip (Fig. 6f). One small papilla on anterior parapodial surface from chaetiger 1 backwards (Fig. 6g). Composite falcigers numbering 5-7 per fascicle; distal end of shaft inflated, with 3-4 indentations (Fig. 6h). Blades unidentate with long, recurved tip; no spinulation observed along cutting margin. Blades up to $17 \mu \mathrm{m}$ long, the ventralmost ones slightly shorter.

Pygidium terminal, with two small dorsal papillae, a pair of lateral anal cirri, similar in size and shape to the lateralmost macrotubercles with terminal papilla, and midventral digitiform anal cirrus (Fig. 6i). 


\section{Etymology}

This species is named after Dr. Gesa Hartmann-Schröder because of her many contributions to the knowledge of Antarctic polychaetes in general, and of sphaerodorids in particular.

\section{Remarks}

The only short-body sphaerodorid genus with more than two rows of macrotubercles bearing a terminal papilla is Sphaerephesia Fauchald, 1972 (Fauchald 1974; Kudenov 1987). The five known species of the genus, namely S. longisetis Fauchald, 1972, S. similisetis Fauchald, 1972, S.

chilensis Fauchald, 1974, S. fauchaldi Kudenov, 1987 and S. regularis Böggemann, 2009present four longitudinal rows of macrotubercles, all provided with button-shaped or stout terminal papilla, and bear composite chaetae (Fauchald 1972; Kudenov 1987; Böggemann 2009); dorsal surfaces may present a number of microtubercles that are provided with a distal papilla (S. longisetis) or may be
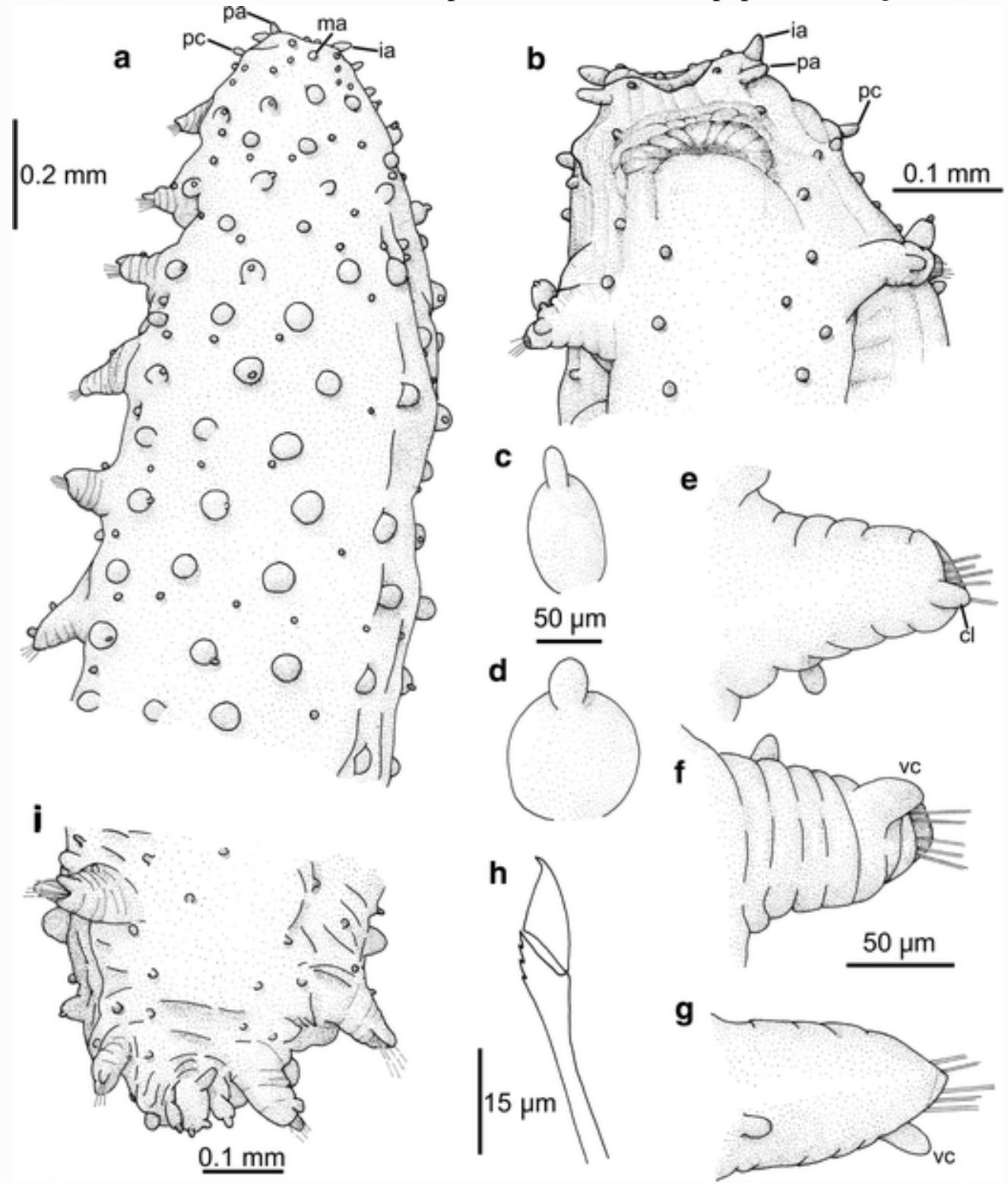

Fig. 6 Sphaerephesiagesae sp. nov. a anterior end, dorsal view, b anterior end, ventral view, $\mathbf{c}$ digitiform lateral macrotubercle with terminal papilla, $\mathbf{d}$ spherical latero-dorsal macrotubercle with terminal papilla, e parapodium, chaetiger 5, dorsal view, $\mathbf{f}$ parapodium, chaetiger 8, ventral view, $\mathbf{g}$ parapodium, chaetiger 4, anterior view, $\mathbf{h}$ composite chaeta, $\mathbf{i}$ distal end, ventral view 
more or less capitated (S. fauchaldi). Because of the presence of more than two longitudinal rows of macrotubercles with terminal papilla and composite chaetae, the new species described here is tentatively included in that genus. Nevertheless, Sphaerephesia gesae sp. nov. differs from all other Sphaerephesia species in bearing more than four longitudinal rows of macrotubercles and in having only some macrotubercles of each parapodial area provided with a terminal papilla, which is longer than those reported from other species of Sphaerephesia. Indeed, the regular presence of two macrotubercles with a terminal papilla on each side of each row on the parapodial area suggests that this condition is not an artifact related to the fixation of the specimens. These features make $S$. gesae sp. nov. unique among all described sphaerodorids. On the other hand, the presence of more than four rows of macrotubercles arranged in a zig-zag pattern is a feature found in several species of the genus Sphaerodoropsis. In addition, the appearance and features of the parapodia of S. gesaesp. nov. are similar to those described from a number of Sphaerodoropsis species, namely $S$. bisphaeroserialis (Hartmann-Schröder, 1974), S. arctowskyensis Hartmann-Schröder and Rosenfeldt, 1988, S. translucida Borowski, 1994 and S. garciaalvarezi Moreira et al. 2004. The only species of Sphaerodoropsis having macrotubercles arranged in more or less a zig-zag pattern and bearing a terminal papilla is $S$. translucida, according to the redescription provided by Böggemann (2009). This species was originally described as having the macrotubercles with "distal end more or less set off, but without terminal papilla" (Borowski 1994), and not arranged following a definite pattern. Böggemann (2009) states that the possession of macrotubercles provided with a terminal papilla is in contrast to the accepted diagnosis of the genus Sphaerodoropsis. Because of that, $S$. gesae sp. nov. was not included in Sphaerodoropsis. In fact, Sphaerodoropsis is now composed by an assemblage of species which might represent several different genera. For example, species can be grouped according to the number and arrangement of macrotubercles (Borowski 1994). In addition,

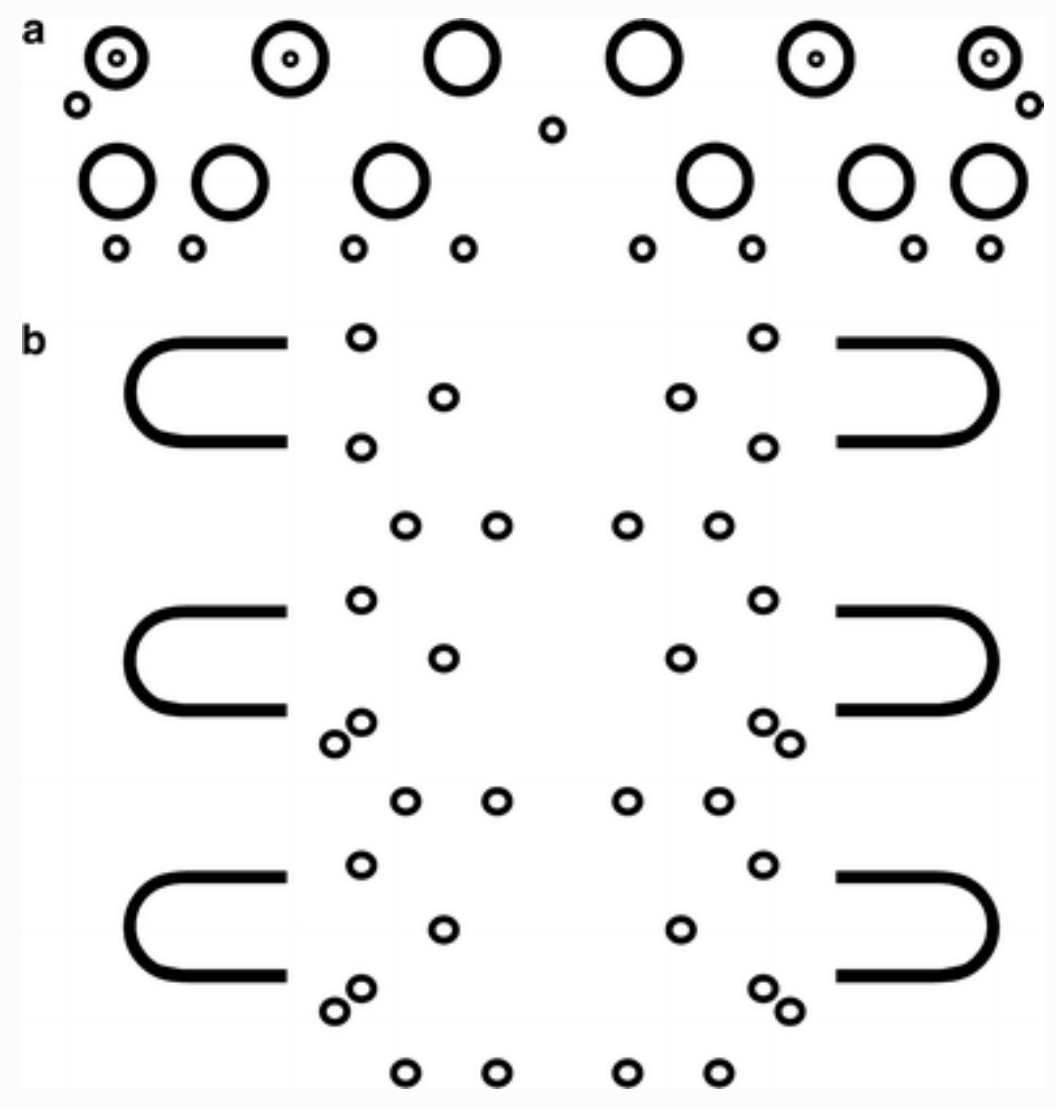

Fig. 7 Sphaerephesiagesae sp. nov. Schematic arrangement of: a dorsal macrotubercles and papillae, chaetiger 6, b ventral papillae, chaetigers 4-6. Symbols: large circle, smooth macrotubercle; large circle with inner small circle, macrotubercle with terminal papilla; small circle, dorsal/ventral papilla 
some species with two transversal rows of macrotubercles arranged in a zig-zag pattern seem to differ from the others in having inflated ventral parapodial cirri in the 6th chaetiger, which could be interpreted as a penis structure (Moreira et al. 2004; Böggemann 2009). At this point, a revision of the whole family and of this genus, in particular, is needed (Borowski 1994; Aguado and Rouse 2006).

As only one specimen of $S$. gesae sp. nov. is available, no new genus has been erected for this species in spite of its unique features among sphaerodorids, mostly regarding the number and shape of dorsal macrotubercles. Indeed, examination of further material is necessary to assess the true position of this and other species within the Sphaerodoridae.

\section{Ecology and distribution}

This species is only known from the Bellingshausen Sea, in muddy fine sand at depths of $612-620 \mathrm{~m}$.

\section{General remarks}

Three genera of sphaerodorid polychaetes, represented by five species, are reported here for the first time for the Bellingshausen Sea; two of them are new to science. This raises the total number of known Antarctic sphaerodorids to 15. Two of these species have previously been reported from other Antarctic areas, namely Ephesiella muehlenhardtae and Clavodorum polypapillata; the latter has also been suggested to be present in the southern Atlantic Ocean (Schüller and Ebbe 2007). In fact, most of the sphaerodorid species previously described from Antarctic and Subantarctic waters have not been reported yet from other latitudes, the exception being Sphaerodoropsis parva (Ehlers, 1913), which has been cited in Australia and southern South America (Hartmann-Schröder and Rosenfeldt 1988) and in the eastern North Atlantic (Desbruyères 1980). However, we suspect that non-Antarctic records of this species might refer to other similar taxa, whether they represent new taxa or not. Thus, the specimens named $S$. parva by Wesenberg-Lund (1962) from the coast of Chile turned out to be a new species after the world revision of this family done by Fauchald (1974) and named Sphaerephesia chilensis Fauchald, 1974. Similarly, other polychaete taxa thought as having a wide distribution and previously reported from the Southern Ocean might actually not be represented there. This is the case of the northern trichobranchid Terebellides stroemii Sars, 1835 which was supposed to be represented at southern latitudes by the subspecies T. stroemii kerguelensis McIntosh, 1885, which recently Parapar and Moreira (2008), after revision of the type material, proposed elevated to the species rank leaving the distribution of $T$. stroemiilimited to northern latitudes.

The sphaerodorid fauna from the Southern Ocean seems therefore to be highly endemic (Fauchald 1974; Schüller and Ebbe 2007). Schüller and Ebbe (2007) suggest that this fact might be the result of radiation events related to the recolonization of Southern Ocean sediments. Nevertheless, the true degree of endemism in this area cannot be fully assessed yet due to the many gaps in our knowledge of the taxonomy, distribution and ecology of sphaerodorids that still exist. On the one hand, these polychaetes are easily overlooked in sediment samples due to their small body size, and they thus need to be sampled adequately, for example, by means of gear like the Epibenthic Sledge which has previously demonstrated its usefulness in obtaining large numbers of specimens of this family of polychaetes (Schüller and Ebbe 2007; Parapar and Moreira 2009). On the other hand, the state of preservation of the specimens makes identification to the species level difficult; many individuals appear contracted, and characters of high taxonomic relevance such as the arrangement of tubercles and papillae are difficult to ascertain. In addition, Clarke (2008) points out that cryptic species may be common in Antarctic benthic faunas as suggested by molecular studies. Indeed, many sphaerodorid species are morphologically very similar and in many cases, due to this, are 
distinguished only according to subtle differences. Therefore, we believe that future morphological work should be combined with molecular analyses in order to assess the identity of some taxa and thus determine their true geographic and bathymetric distribution.

Many Antarctic polychaetes are supposed to be distributed only at shelf and slope depths (Brandt et al. 2009). Here, four out of the five sphaerodorid species found were only present on the shelf and slope; it must be taken into account that most of the samples collected in the Bentart 06 expeditions were taken on a limited range of depths (150-2000 m). Nevertheless, it is noteworthy that the only specimen of E. muehlenhardtae was found deeper than $3,000 \mathrm{~m}$, thus greatly extending the previously known depth range of this species, which was reported between 93 and $342 \mathrm{~m}$.

According to the few published papers on a number of benthic taxa, including molluscs (Troncoso et al. 2007; Troncoso and Aldea 2008) and polychaetes (Parapar et al. in press) as well as when considering higher taxonomic categories (Sáiz et al. 2008), the Bellingshausen Sea seems to be a well-defined biogeographical area within the Southern Ocean. This fact has tentatively been related to depth and the very nature of the sediment, which is mostly composed by deposits of foraminiferans and diatoms (Hillenbrand et al. 2003). The presence of the two new sphaerodorid species described here might strengthen this conclusion. However, as explained above, more data are needed to fully assess the biogeographical characteristics of the Bellingshausen Sea, at least in regard to its polychaete fauna.

\section{Acknowledgments}

The authors wish to thank Dr. A. Brandt (Zoological Museum, Hamburg) for the loan of type series of Sphaerodoropsispolypapillata. Many thanks also to A. Castro and C. Sueiro (SAIN, Universidade da Coruña) and R. Barreiro (RIAIDT, Universidade de Santiago de Compostela, Spain) who assisted with the preparation of specimens and use of the SEM, to Y. Lucas for assisting with the preparation of the drawings and to J. García-Carracedo for the translation of several bibliographic references and the revision of the English version of the manuscript. The authors are also grateful to T. Bakken, B. Ebbe and D. Eibye-Jacobsen for their constructive comments on an earlier version of the manuscript. Special thanks to the crew of R/V Hespérides and all the colleagues which collaborated in the Bentart 2006 expedition and especially to Carles San Vicente (Generalitat de Catalunya) and Patrick Arnaud (Station Marine de Endoume, France) who collected the specimens from the Epibenthic Sledge samples. The Bentart expeditions were carried out under the auspices of the Spanish Government through the Ministry of Education and Science and were supported by the Spanish Antarctic Programme (CICYT) (REN 2001-1074/ANT and CGL2004-01856).

\section{References}

Aguado MT, Rouse GW (2006) First record of Sphaerodoridae (Phyllodocida: Annelida) from hydrothermal vents. Zootaxa 1383:1-21

Aguirrezabalaga F, Ceberio A (2005) Sphaerodoropsis amoureuxi and S. stellifer, two new species of Sphaerodoridae (Polychaeta) from the Capbreton Canyon (Bay of Biscay, NE Atlantic). Cah Biol Mar 46:9-20

Arntz WE, Brey T, Gallardo VA (1994) Antarctic Zoobenthos. Oceanogr Mar Biol Annu Rev 32:241304

Averincev VG (1972) Benthic polychaetes Errantia from the Antarctic and Subantarctic collected by the Soviet Antarctic expeditions. Exploration of the fauna of the Seas. Biol Res Sov Antarct Exped 5:88-293 (in Russian) 
Bakken T (2002) Sphaerodoridae (Annelida: Polychaeta) from the BIOSHELF Project, Andaman Sea, Thailand. Phuket Mar Biol Center Res Spec Publ 24:197-204

Benham WB (1921) Polychaeta. Australasian Antarctic Expedition 1911-14 under the leadership of Sir Douglas Mawson, D.Sc. B.E. Sci Rep Ser C 6:1-128

Böggemann M (2009) Polychaetes (Annelida) of the abyssal SE Atlantic. Org Div Evol 9:251-428

Borowski C (1994) Three new deep-sea species of Sphaerodoridae (Annelida, Polychaeta) from the eastern tropical South Pacific. Zool Scr 23:193-203

Brandt A, De Broyer C, Gooday AJ, Hilbig B, Thomson MRA (2004) Introduction to ANDEEP (ANtarctic benthic DEEP-sea biodiversity: colonization history and recent community patterns)-a tribute to Howard L. Sanders. Deep Sea Res II 51(14-16):1457-1465

Brandt A, Linse K, Schüller M (2009) Bathymetric distribution patterns of Southern Ocean macrofaunal taxa: Bivalvia, Gastropoda, Isopoda and Polychaeta. Deep Sea Res I 56:2013-2025

Cartes JE, Sorbe JC, Sarda F (1994) Spatial distribution of deep-sea decapods and euphausiids near the bottom in the northwestern Mediterranean. J Exp Mar Biol Ecol 179:131-144

Clarke A (2008) Antarctic marine benthic diversity: patterns and processes. J Exp Mar Biol Ecol 366:48-55

Desbruyères D (1980) Sphaerodoridae (Annélides Polychètes) profonds du Nord-Est Atlantique. Bull Mus Natn Hist Nat, Paris, 4e sér, 2, section A(1):109-128

Ehlers E (1913) Die Polychaeten-Sammlungen der Deutschen Südpolar-Expedition 1901-1903. Dtsch Südpolar Exped 13:397-598

Fauchald K (1972) Benthic polychaetous annelids from deep water off western Mexico and adjacent areas in the eastern Pacific Ocean. Allan Hancock Monogr Mar Biol 7:1-575

Fauchald K (1974) Sphaerodoridae (Polychaeta: Errantia) from world-wide areas. J Nat Hist 8:257-289

Hartman O (1967) Polychaetous annelids collected by the USNS Eltanin and Staten Island cruises, chiefly Antarctic seas. Allan Hancock Monogr Mar Biol 2:1-387

Hartman O (1978) Polychaeta from the Weddell Sea quadrant, Antarctica. Paper 4. Biology of the Antarctic Seas VI. Antarct Res Ser 26:125-223

Hartmann-Schröder G, Rosenfeldt P (1988) Die Polychaeten der "Polarstern"-Reise ANTIII/2 in die Antarktis 1984. Teil 1: Euphrosinidae bis Chaetopteridae. Mitt Hamb Zool Mus Inst 85:25-72

Hartmann-Schröder G, Rosenfeldt P (1990) Die Polychaeten der Walter Herwig-Reise 68/1 nach Elephant Island (Antarktis) 1985 Teil 1: Aphroditidae bis Cirratulidae. Mitt Hamb Zool Mus Inst $87: 89-122$

Hartmann-Schröder G, Rosenfeldt P (1992) Die Polychaten der "Polarstern"-Reise ANT V/1 in die Antarktis 1986. Teil 1: Euphrosinidae bis Iphitimidae. Mitt Hamb Zool Mus Inst 89:85-124

Hilbig B, Gerdes D, Montiel A (2006) Distribution patterns and biodiversity in polychaete communities of the Weddell Sea and Antarctic Peninsula area (Southern Ocean). J Mar Biol Assoc UK 86:711725

Hillenbrand C-D, Grobe H, Diekmann B, Kuhn G, Fütterer DK (2003) Distribution of clay minerals and proxies for productivity in surface sediments of the Bellingshausen and Amundsen seas (West Antarctica) - relation to modern environmental conditions. Mar Geol 193:253-271

Kudenov JD (1987) Five new species of Sphaerodoridae (Annelida: Polychaeta) from the Gulf of Mexico. Proc Biol Soc Wash 100:927-935

Martin D, Alva V (1988) Un polychète nouveau Sphaerodorum ophiurophoretos nov. sp. (Polychaeta: Sphaerodoridae), symbiotique de l'ophiure Amphipholis squamata (Delle Chiaje, 1828). Bull Koninklijk Belg Inst Natur Biol 58:45-49

Moreira J, Cacabelos E, Troncoso JS (2004) A new species of Sphaerodoropsis (Polychaeta: Sphaerodoridae) from north-east Atlantic, with comments on other species of the genus. J Mar Biol Assoc UK 84(5):995-1000 
Parapar J, Moreira J (2009) Polychaeta of the 'DIVA-Artabria I' project (cruise 2002) in the continental shelf and upper slope off Galicia (NW Spain). Cah Biol Mar 50:57-78

Parapar J, Moreira J (2008) Redescription of Terebellides kerguelensis stat. nov. McIntosh, 1885 (Polychaeta: Trichobranchidae) from Antarctic and subantarctic waters. Helg Mar Res 62:143-152

Parapar J, López E, Gambi MC, Núñez J, Ramos A (in press) Quantitative analysis of soft-bottom polychaetes of the Bellingshausen Sea and Gerlache Strait (Antarctica). Pol Biol

Pleijel F (2001) Sphaerodoridae Malmgren, 1867. In: Rouse GW, Pleijel F (eds) Polychaetes. Oxford University Press, Oxford, pp 136-138

Ruderman L (1911) Recherches sur Ephesia gracilis Rathke, Annélide polychète de la familie des sphaerodorides: morphologie, anatomie, histology. Mém Soc zool Fr 24:1-96

Saiz JI, García FJ, Manjón-Cabeza ME, Parapar J, Peña-Cantero A, Saucède T, Troncoso J, Ramos A (2008) Community structure and spatial distribution of benthic fauna in the Bellingshausen Sea (West Antarctica). Polar Biol 31:735-743

San Vicente C, Munilla T, Corbera J, Sorbe JC, Ramos A (2009) Suprabenthic fauna from the Bellingshausen Sea and western Antarctic Peninsula: spatial distribution and community structure. Sci Mar 73:357-368

Schüller M, Ebbe B (2007) Global distributional patterns of selected deep-sea Polychaeta (Annelida) from the Southern Ocean. Deep Sea Res II 54:1737-1751

Troncoso JS, Aldea C (2008) Macrobenthic mollusc assemblages and diversity in the West Antarctica from the South Shetland Islands to the Bellingshausen Sea. Polar Biol 31:1253-1265

Troncoso JS, Aldea C, Arnaud P, Ramos A, García F (2007) Quantitative analysis of soft-bottom molluscs in the Bellingshausen Sea and around Peter I Island. Polar Res 26:126-134

Wesenberg-Lund E (1962) Polychaeta Errantia. Reports of the Lund University Chile Expedition 19481949 (43). Lunds Universitets Årsskrift NF Avd 2, 57(12):1-139 